\title{
Socially Centred Fiscal Policy and its Role in Implementing the Idea of Society
}

\author{
A. Kornienko ${ }^{a}$, Z. Antonova ${ }^{a *}$, O. Fofanov ${ }^{a}$, N. Kachalov ${ }^{a}$, B. Kaliuzhniy ${ }^{\text {a }}$ \\ * Corresponding author: Z. Antonova, economics@tpu.ru \\ ${ }^{a}$ National Research Tomsk Polytechnic University, Lenin Avenue, 30, Tomsk, 634050, Russia, E-mail address: \\ economics@tpu.ru, Tel.: +7-913-817-1564
}

\section{Abstract}

http://dx.doi.org/10.15405/epsbs.2016.02.7

The issues of social policy reforming in the Russian Federation at the present stage of development have been considered. The basic elements of the social policy of any state have been noted. Social policy in Russia in the last twenty years has been investigated.

C 2016 Published by Future Academy www.FutureAcademy.org.uk

Keywords: Social policy, reforming of budgetary organizations, public goods, private goods, socially important goods, government regulation of the economy, life quality indicators.

\section{Introduction}

The growth of the country's welfare is a main condition for economic development as well. Social policy reforming objectives are timely and relevant during the period or new industrial era. Without reforms in education, healthcare and culture we won't be able to build a social state. Therefore the social policy is the most important tool for regulation of all social relations and processes in the country. Thus, socio-cultural modernization is a key element of the economic growth and nation's prosperity as well as all initiatives in terms of new technical modernization of Russia.

\section{State social policy.}

Social policy can be interpreted as a part of the internal policy of the state, embodied in social programs and practices, and regulating relations in society for the benefit and in the interests of major social groups; a set of rules, certain principles and approaches to solving social problems. Social policy helps to resolve the contradictions between the current and future interests of the community, various 
classes, social strata and groups, public institutions; takes into account, forecasts, reduces and corrects the inevitable "cost" of society for social stability and progress. As a set of measures to implement the vital needs of the population, social policy is designed to ensure the repeatability of the social resources which the state relies on, predetermines the development and stability of the social system. Social policy possesses various dimensions (economic, organizational, legal, social, cultural, environmental, and personal) and is carried out by means of specific mechanisms of the state and public administration, and management via the development and implementation of legislation in the field of social relations, adoption of social programs, certain solutions for social development. Effective social policy is based on the principle of social justice. It is assumed that actual social interests and needs in a given historical period and the specific situation should be implemented. There are two related points of social justice - reproductive and distributive justice. The first contains the requirements for a person from the community; it indicates the need for socially useful activity. Its optimal formula is "from each according to his ability". The second involves the responsibility of society to the individual and is expressed in the formula "to each according to his deserts". It is not about equalization, but the "proportional" justice, according to which those who "suffered heavily are plentiful" but those who "suffered lightly are scanty". At different historical stages, each of the designated forms of social justice is filled with specific content. Thus, market relations modify them in such a way that capital becomes the main factor of production and distribution. However, the logic of market relations highlights the need for social protection of humans outside the market that do not have the possibility of existence at the level of minimum living standard.

State social policy is one of the most important instruments to control processes related to human life, health and welfare. Social policy takes one of the main places in the internal policy of any country. The main goal of social policy is to develop state regulation of social relations and processes.

The main feature of social policy is reflecting the needs and economic interests of classes and groups in social relations and ensuring conditions for their normal life, since no development is possible without human factor. Human factor is "a powerful instrument for the state economic growth" (Orlov, 2012).

\section{Modernization of social development}

To date, highly relevant issue is social service reforming, or, as it seems to the authors, so-called social and cultural modernization, which is an integral part of any economic growth and technical modernization initiatives. As noted by A. Auzen, “...solution of the modernization problem in each case is unique, due to the specific situation... cannot be standardized...” (Auzen, (2012). The first concept of modernization was introduced by M. Weber, who defined it as a conversion of the existing society to modern society (Weber, 1990). In the middle of the last century, S. Lipset hypothesized social modernization, which linked the categories such as economic growth and distribution of estate among citizens (Lipset, 2012).

Scientists still hold a discussion about this hypothesis, though, in our opinion, at the present stage of the development of Russia it is quite valid and relevant. Is the country capable of ensuring economic 
http://dx.doi.org/10.15405/epsbs.2016.02.7

eISSN: 2357-1330 / Corresponding Author: A. Kornienko,Email: economics@tpu.ru

Selection and peer-review under responsibility of the Organizing Committee of the conference

growth, if social policy is imperfect, reforming increases social tension, and "investments in human capital, health and welfare decline?" (Rozmainsky, 2011).

The hypothesis of social modernization should reflect social orientation in the country, or so-called social doctrine, for a sufficiently long period of time. Agreeing with Professor Bobkov, it can be noted that the objective of social doctrine or social modernization is "to achieve high quality of life for each person, family...to preserve humanist society, providing basic social security...” (Bobkov, 2013). A new version of the long-term development strategy for Russia, where the government has taken into account the effects of the crisis of 2008-2009, states "Russia sets ambitious but achievable long-term development goals - to ensure a high level of welfare, to enhance the country's role as one of the global leaders. ...The only possible way to achieve these goals is to move the economy to an innovative socially-oriented model of development” (Innovative Russia-2020, 2010).

As Professor J. Katz notes "social market economy is a system in which the activity of all economic entities is regulated by market and state in the interests of population. It is distinguished by a high level of entrepreneurship, welfare, health, and protection of the rights and freedoms of all citizens" (Katz, 2015).

Accordingly, a social welfare state should guarantee the income and social protection for the entire population of Russia. The concept of the social welfare state is criticized by many western scientists. They believe that socially centered economy hinders economic growth, inhibits the growth of economic efficiency. But we know that, for example, Sweden and Germany can be considered as the social welfare states. They are successfully developing and the citizens living there have enough high quality of life. If we look at our country, we can agree with S. Gubanov that our "model has reached the point: now there is neither growth nor development" (Gubanov, 2014).

Social relations arise in the process of communication between people in different social groups, between nations, professional groups, and families and within families. Living conditions make health, wealth, spiritual world, and field of activities, which ensure whatever is required for the existence and the comprehensive development of human. Thus, the object of social policy is the country population, being both the consumer power of society and the subject of needs and consumption.

\section{Relationship between social and economic state policy}

State policy is implemented in various areas according to its economic objectives. Therefore, policy of economic growth, policy of economic efficiency, policy of full employment, policy of stable prices, policy of economic security, and policy of equitable distribution of income are allocated. All these areas of public policy, setting and solving seemingly different goals, are, however, closely interrelated (Akhinov, Myslyaeva, 2011).

The dialectical relationship between social and economic policy of the state is very important for society and its development. This relationship is shown in the following:

- The final result of economic policy is the state regulation of able-bodied population to create material and spiritual wealth. At the same time, human welfare is considered as 
one of the main results; the other result - state economic growth - is the sequence of welfare (the problems of economic growth in modern conditions are set out by the authors (Antonova, Komarevtseva, Livshits, 2012) in more detail).

- Social policy is related to the influence on using material and spiritual wealth, and human relations in order to use them; that is, based on the principles of social justice defining the living conditions of all members of society.

It can be concluded that all types of state policy are interrelated and interdependent: either the result or the beginning of an action.

Relationship between society welfare and economic growth is noted by L. Shipovich: “...welfare directly depends on the level of development of productive forces and the nature of economic relations. The population well-being is highly dependent on the efficiency of social and economic policy. Thus, welfare is a criterion for the economic growth of national economy" (Shipovich, 2013). Therefore, when the government plans economic growth, it is necessary to take into account the society welfare at a given time.

Under market conditions, social policy should be aimed at creating the preconditions for meeting the basic population needs, on the one hand, and ensuring, on the other hand, the social peace between various social groups, classes or nations, by means of consensus. Unless this very important strategic goal is achieved, it is not possible to arrange the efficient functioning of state market economy, to prevent and smooth out various social conflicts that arise in society. These conflicts are social risks, which find expression in religious intolerance, nationalism, domination of the financial oligarchy. Today we see the fusion of government and commercial interests of business and the authorities, which do not include the population interests. "Living standards of at least $40 \%$ of Russians have fallen over the past 20 years of capitalist reforms. The contradictions between labor and capital, the majority of population and financial oligarchy have also sharpened" (Bobkov, 2013). Russian business is not focused on the interests of society and its goal - to maximize profits stemming from the requirements of economic laws which are inherent in market economy, there is no other alternative. According to P.K. Roberst, "commitment to market paradise is a mistake, but profit is no longer a measure of social well-being, as it is achieved by substituting for cheap foreign labor leading to a consequent reduction in consumer purchasing power and rising social inequality" (Roberts, 2014).

In order to implement social policy in any country, the following basic principles should be taken 
http://dx.doi.org/10.15405/epsbs.2016.02.7

eISSN: 2357-1330 / Corresponding Author: A. Kornienko,Email: economics@tpu.ru

Selection and peer-review under responsibility of the Organizing Committee of the conference

into account:

- Ensuring economic freedoms for humans, citizens of wage labor, whose interests are expressed by the free trade unions, representing them in the system of social partnership.

- Confidence in the fact that supply and demand, open price and competition will be established in the markets.

- The state responsibility for ensuring the free play of market forces, creating conditions for normal economic and social life in the country.

- Increased load on the most able-bodied members of society, in order to help other less able-bodied part of the population: the sick, the disabled ones and others.

- The participation of labor collectives and individual employees in decision-making, organizing company activities, as well as in public and social life via strengthening civil society institutions.

We believe that state social policy should, firstly, create conditions for the income growth in accordance with the labor contribution of each person and capital they hold; secondly, improve the economic and social responsibility of every society member, thereby, preventing social dependency; and thirdly, have reliable tools of social protection.

\section{Development of strategic plans for social policy in Russia}

Strategic and tactical goals of social policy of the Russian Federation have been reflected in the programs of social reforms, for the periods of 1996-2000 and 2000-2008, as well as in the State development concept up to 2020 (Innovative Russia-2020, 2010).

The basis for achieving economic goals and activities aimed at implementing the strategic plans of social policy is formed by such factors as:

- Annual growth of GDP, capital investments, production and sales in the most strategic sectors of the economy.

- $\quad$ Reduction of the state budget deficit.

- Disinflation.

- Consolidation of ruble position in the domestic and foreign markets.

- Gaining share of final consumption expenditure of households in the current GDP.

It was planned to achieve the objectives of social policy in accordance with the program of social reforms in Russia in stages.

The first stage was designed for 1996-1997. Peculiarities of this period primarily reflected the limitations of resource potential of the Russian economy. Therefore, the main goals and objectives 
were fairly localized, and limited. The primary goals of the social policy in this period were as follows: poverty reduction, prevention of unemployment growth, strengthening citizens' rights in terms of employment and social protection, stabilization of the population living standard.

The second stage covers the years of 1998-2000. According to the politicians of that time, it was expected to take place in the best economic conditions for the country than the previous one. At this stage, it was scheduled to solve such problems as raise in salaries and pensions to the subsistence level, creation of a full-fledged protection system of labor rights of citizens based on the new Labor Code. Many scientists regard these stages of social policy as a leap into the market that resulted in "shock therapy" for the country. In the next stage (2000-2008) attention of the state policy was paid to doubling GDP to a level that, unfortunately, in the medium-term program of the Government of Russia was not reflected with sufficient specifics of the base year, although some parameters came up with those in 1990. The global financial crisis prevented from implementing these plans. Later on, the Government adopted a new strategy - the concept of sustainable development. "State development concept up to 2020 " states "...the society based on trust and responsibility will be created in Russia, including public confidence in the state and private economic institutions. Social polarization will significantly decrease. This will be achieved by ensuring equal opportunities for social mobility of talented representatives of all society strata, implementing social policy to support vulnerable groups and carrying out policy aimed at the migrants' integration. Share of the middle class will make more than half of the population, with a significant part of the middle class consisting of people involved in creating the new economy of knowledge, technology and human development" (The concept of longterm socio-economic development of the Russian Federation for the period up to 2020, 2009). However, it is difficult to hope that these plans will be implemented in the short term. So, why did not the reforms of the previous years yield the positive results for the country? Let's try to understand the past and connect it with the present and future research issues.

The constitutional formula "Russian Federation - social welfare state whose policy is aimed at creating conditions for dignified life and free human development" was sidelined in order of political importance to the detriment of social policy in favor of solving the problems of macroeconomic policy.

In the official Russian government programs since 2000, the social welfare state has been converted from the state taking care of its citizens to the supplementary or "subsidiary" state. Let's consider the difference between these two types of state. The former state was obliged to take care of all society members and meet some human needs at the expense of its own treasury, treasury of the state; on the contrary, the latter was obliged to care only about the population subsidies not to the entire population, but some social strata, identified by the state itself.

The government in the post-reform period identified itself the liberal care scale for the poor and the sick ones, citizens unable to earn their living in the new market environment, with its rules and laws that were unknown to them, as the latter were of state-planned economy descents. This regulation was then the main concern of the government. Along with that the state would have been obliged to take care of production setting of goods and services required for the country population, which the government provided from the budget funds. Instead, the government began to shift financial obligations from the state budget to the household budgets. Thus, the government purely subsidized the 
http://dx.doi.org/10.15405/epsbs.2016.02.7

eISSN: 2357-1330 / Corresponding Author: A. Kornienko,Email: economics@tpu.ru

Selection and peer-review under responsibility of the Organizing Committee of the conference

state obligations which were worth subsidizing according to the state. This situation currently remains unchanged.

Federal Law № 83-FZ dated 08.05.2010 “On amendments to certain legislative acts of the Russian Federation due to the improvement of legal status of the government (municipal) institutions" (Federal Law № 83-FZ dated 08.05.2010 "On amendments to certain legislative acts of the Russian Federation due to the improvement of legal status of the government (municipal) institutions”, 2010) is a sort of new social reform, the general concept of which reflects the idea of subsidizing under the new state policy. Besides, the concept of such policy largely confers immunity from the state social obligations towards the country population. The law changes the legal status of government and municipal institutions that provided social services for the population. The given law will have a profound impact on the economic and financial activity of organizations representing the public (state and municipal) sector of the socio-economic system of our country. According to the law, significant innovations were introduced to the public services sector. These innovations are primarily related to such branches of economy as education, health care, culture, and science. The given reform seems to be aimed at increasing the affordability and quality of public services to population of Russia. But then, the question arises, what is the cost of these services, and how effective this reform is in terms of social policy and guarantees. According to our government, an efficiency criterion of the reform is sufficient volume of high-quality public goods and their accessibility for all Russians. However, in our opinion, the actual criterion of efficiency would be to provide sufficient volume of free or at least favorable public goods to the country population, as welfare is a provision of the country population or a certain citizen with social and material goods required for their living. Pareto principle confirms that "wellbeing of society makes maximum, and allocation of resources is optimal, if any change in this allocation does not worsen the welfare of at least one subject of the economy" (Atkinson, Stiglitz, 1995).

Under federal law "On the reform of the scope of public services" (Federal Law № 83-FZ dated 08.05.2010 "On amendments to certain legislative acts of the Russian Federation due to the improvement of legal status of the government (municipal) institutions", 2010), which are public institutions, new and profound innovations are introduced:

- The number of founders of public services organizations has expanded. Individuals and foreign commercial organizations can be included in this register apart from the common state and municipal authorities.

- Mechanisms to provide financial resources for such organizations have changed based on financing norms directively approved and established by the government institutions.

- New types of institutions of public services have been identified - autonomous institutions in education, health care, and culture, whose activities are state-subsidized on the basis of capitation standard rate. Herein, not the organization itself, but only a well-defined group of clients becomes financed. Moreover, in respect of these institutions bankruptcy proceeding has been provided.

- According to the law, autonomous institutions have been provided with two sources of 
funding: budget and other "income generating activities". Unlike the budgetary institutions, these revenues come into an autonomous institution that fully disposes of them for the sake of its own core objectives.

- The property of state-owned and budgetary institutions is settled on them based on operational management.

Under this law, government and municipal institutions are not funded by budgets but via the mechanism of budget subsidies in order to perform tasks of the state or municipality.

The new budgetary reform allows legislatively executing a piece of work or providing services in budgetary institutions that represent their core activity for a fee in addition to the tasks offered by municipality or public authority. This source of additional financial resources in the budgetary institutions is economically based on market relations governed "from the top" rather than by market competition, i.e. fee for their work beyond the tasks is set by the authority, which exercises the powers of a founder of the budget organization. Therefore, it is unlikely that prices will be set equitably and effectively.

\section{Conclusion}

It has been hypothesized that the factors of social culture, such as welfare, well-being and health, can be among the resources of modern neoindustrialization and its capital. Knowledge of humans influences the performance in the scope of their activity but their "health" capital determines the time period required to provide for them while working. The social policy of Russia in terms of accumulating such capital as welfare and health, does not take into account great number of factors that determine life quality. It has been proved that the reform of budgetary institutions at the present stage of development is inefficient, as many of the problems have remained unchanged or even increased due to weak legislative base, and mismatch with other legislative acts. The true purpose of the reform has become obvious - state commitment to shuffle off the social function on local authorities and the population itself. Social reforms undertaken by the Government of Russia will never meet the expectations of population, unless the changes are made. Thus, the reform of public service aims to improve its quality and accessibility. This fact, according to the reformers, will be considered as a criterion of its efficiency. However, in our opinion, it will be the measure of reform quality, if only high-quality and affordable services and public goods become available, free of charge or on favorable terms, for the part of the population that really needs it. Implementation of these measures hinges on the political will. Today, these measures need to be immediately implemented; the economic community should convince of it the national political leaders.

\section{References}

Orlov, A. (2012). Economic development depends on human factor. The Economist. 12, 51-56.

Auzen, A. (2012). Sociocultural formula of economic modernization development. Questions of economy. 5, 3844.

Weber, M. (1990).The Protestant ethic and spirit of Capitalism. M.: Center for Humanities Research, 360 p.

Lipset, S. (2012). Some social conditions of democracy: Economic development and political legitimacy: transl. from English. The concept of modernization in foreign socio-political theory, 1950-1960. Collection of translations, RAS INION. Moscow, 35-86.

Rozmainsky, I. (2011). Why health capital is accumulated in the developed countries and "eaten through" in post- 
http://dx.doi.org/10.15405/epsbs.2016.02.7

eISSN: 2357-1330 / Corresponding Author: A. Kornienko,Email: economics@tpu.ru

Selection and peer-review under responsibility of the Organizing Committee of the conference

Soviet Russia. Questions of economy. 10, 113-131.

Bobkov, V. (2013). On social dimension of the new stage of development. The Economist. 5, 61-72.

Innovative Russia-2020 (2010). Ministry of Economic Development. [Online] http://www.economy.gov.ru/activity/sections/innovations/djc201012031_016 (22 February, 2015).

Available: 